\title{
Polyamines in Parkinson's Disease: Their Role in Oxidative Stress Induction and Protein Aggregation
}

\author{
Marina G. Makletsova ${ }^{a}$, Sergei P. Syatkin ${ }^{b}$, Vsevolod V. Poleshchuk ${ }^{\mathrm{a}}$, Guzel R. Urazgildeeva ${ }^{\mathrm{a}, \mathrm{c}}$, \\ Larisa A. Chigaleychik ${ }^{\mathrm{a}}$, Christina Y. Sungrapova ${ }^{\mathrm{b}}$, Sergei N. Illarioshkin ${ }^{\mathrm{a}}$
}

\begin{abstract}
Parkinson's disease (PD) is a systemic neurodegenerative disease characterized by tremor, rigidity, bradykinesia, and stooping posture. When more than $60 \%$ of dopaminergic neurons in the substantia nigra of the brain have died, motor symptoms manifest in PD. Currently, oxidative stress (OS) is considered to be one of the leading factors provoking death of dopaminergic neurons in PD. This review is concerned with the role of polyamines in $\mathrm{PD}$, especially focusing on their role in OS induction. Polyamines (putrescine, cadaverine, spermidine and spermine) are involved in many molecular mechanisms, including cell proliferation and differentiation, gene transcription and translation, modulation of the functional activity of ion channels and receptors, and other vital processes. It is worth noting that under physiological conditions polyamines are antioxidants. It has been shown that spermine oxidase (SMOX) is up-regulated in $\mathrm{PD}$, activating polyamine breakdown, which leads to excessive formation of toxic aldehydes (such as acrolein), $\mathrm{H}_{2} \mathrm{O}_{2}$ (a strong cytostatic) and ammonia (a toxic substance). Polyamines are also involved in the pathogenetic mechanism of $\alpha$-synuclein modification resulting in the formation of Lewy bodies. This review provides data on the changes in polyamine levels at later stages of the disease. The review also examines the role of polyamines, as gliotransmitters, in regulating neural function and vice versa. The mechanisms of polyamine "pumping" from neurons to glia can be considered factors of OS regulation in neurons. Prolonged accumulation of polyamines in glia can lead to oxidation of polyamines and therefore potentially to gliosis in PD. The exact mechanisms of this process are, however, not clear. Answering the questions regarding the role of polyamines in gliosis development and pathogenesis of $\mathrm{PD}$ is necessary for treating cognitive impairment in patients with $\mathrm{PD}$, which is particularly important.
\end{abstract}

Keywords: Parkinson's disease; Spermine; Spermidine; Putrescine;

Manuscript submitted November 11, 2018, accepted December 20, 2018

${ }^{a}$ Research Center of Neurology, Volokolamskoe sh. 80, Moscow 125367, Russia

'Peoples' Friendship University of Russia (RUDN University), 6 MiklukhoMaklaya Street, Moscow 117198, Russia

${ }^{\mathrm{c} C o r r e s p o n d i n g ~ A u t h o r: ~ G u z e l ~ R . ~ U r a z g i l d e e v a, ~ R e s e a r c h ~ C e n t e r ~ o f ~ N e u r o l-~}$ ogy, Volokolamskoe sh. 80, Moscow 125367, Russia.

Email: guliaurasgildeeva@gmail.com

doi: https://doi.org/10.14740/jnr509
Polyamines; Oxidative stress

\section{Introduction}

The year 2017 marked the 200-year anniversary of the description of "paralysis agitans" by the English physician James Parkinson. The condition was subsequently named after him and is now called Parkinson's disease (PD) [1, 2]. PD is a progressive neurodegenerative disorder affecting more than six million people over the age of 60 [1]. Taking into consideration the increase in life expectancy, many neurologists reasonably predict that by 2030, PD incidence will double [3].

The clinical presentation of PD is characterized by movement disorders such as bradykinesia, muscle stiffness, resting tremor, and postural instability [3-5]. The main cause of PD is the death of nigrostrial dopamine-synthesizing neurons, which leads to dopamine deficiency in the striatum [3]. Moreover, the nigrostriatal degeneration with motion dysfunction is not the only manifestation observed in PD. A significant proportion of patients with PD also suffer from non-motor symptoms, including constipation, depression and cognitive dysfunction.

At present, about 20 genes associated with PD have been identified, but the percentage of hereditary PD forms is only $5-10 \%$, while $90 \%$ are idiopathic forms [6]. In both idiopathic and genetic cases of PD, oxidative stress (OS) is the common basic molecular mechanism that causes a cascade of molecular reactions leading to selective death of neurons in the substantia nigra and their terminals in the striatum. OS inductors are reactive oxygen and nitrogen species, aldehydes, dopamine (when not bound within vesicles and only under specific conditions), defects of mitochondrial DNA and iron deficiency. An imbalance between formation and elimination of reactive oxygen species (ROS) and reduction of antioxidant defense contribute to the pathogenesis of PD. It has been shown that OS is closely related to other aspects of the degenerative process, such as mitochondrial dysfunction, inflammation, atypical protein formation ( $\alpha$-synuclein breakdown, etc.) [4, 5, 7-11].

Pathogenetic mechanisms of OS, pathological modification of $\alpha$-synuclein and other proteins, inflammation and gliosis are the central elements in PD pathogenesis. Investigating them is an important challenge for contemporary neuroscience [12-14]. This review is concerned with the involvement of polyamines in these mechanisms. 


\section{Polyamines}

Polyamines play an important role in numerous molecular mechanisms, including cellular proliferation and differentiation, gene transcription and translation, posttranscriptional modifications [15-17], modulation of ion channel function, cellular signals [18-20], macromolecular synthesis regulation, etc. [21-31]. Their cellular roles include the modulation of ion channels that participate in the excitability of neuronal networks [18-20].

\section{The antioxidant effect of polyamines}

A very significant function of polyamines is their antioxidant action: 1) Spermine, spermidine and putrescine act as free radical scavengers [32-34], and the ability of polyamines to bind toxic aldehydes has been shown [35]; 2) Polyamines have a chelating ability towards metal ions, thereby adjusting the triggering mechanisms of OS [36-39]; and 3) Spermine and spermidine can influence the activity of antioxidant enzymes, interacting with their corresponding DNA [40, 41].

It should be noted that they play an antioxidant role in the brain. Spermine and spermidine enhance antioxidant protection of excitable tissues by modulating glutamate receptors [42], and polyamines are involved in the biosynthesis of other antioxidants. Thus, putrescine is the predominant precursor in the synthesis of homocarnosine in cerebral tissue $[43,44]$, and spermine can influence dopamine binding in synaptic vesicles. Those seem to be the most important effect of polyamines, considering their role in OS induction in PD, as formation of dopamine quinones is currently considered as one of the trigger mechanisms for selective OS [45-47].

For these reasons, there is currently a special emphasis on antioxidating polyamines in nutrition science, preferably those that prevent harmful environmental and dietary effects $[34,41]$.

\section{Polyamines and aging}

Polyamine levels decrease with aging [23, 31, 23, 48-50], which leads to age-related impairment of cognitive and other behavioral reactions [51].

We have previously shown in experiments with senescence-accelerated mice prone (SAMP) and senescence-accelerated mice resistant (SAMR) 1 mice that, polyamine levels were much lower in mice with accelerated type of aging characterized by low antioxidant protective activity than in controls [48].

\section{Polyamines and PD}

PD is generally associated with aging and causes progressive decline of cognitive function [2]. Physical activity (PA) levels have been implicated in cognitive reduction in Parkinson patients via N-methyl-D-aspartate receptor (NMDAR) pathway[52].

\section{Polyamine levels in PD}

At present, several studies on polyamines in brain tissue, cerebrospinal fluid (CSF) and blood of PD patients have been published. Early studies using high-performance liquid chromatography (HPLC) showed an increase in spermidine and spermine in erythrocytes of patients with PD [53]. A study of polyamine contents in the basal ganglia of the human brain showed agerelated conditions, but no significant changes in PD patients [54]. Paik et al studied polyamine concentrations in CSF of $\mathrm{PD}$ patients using gas chromatography and mass spectrometry in ion monitoring mode with N-ethoxycarbonyl/N-pentafluoropropionyl derivatives. CSF polyamine concentrations were significantly different in patients with PD compared with those in the control group [55]. In the PD group, concentrations of putrescine, N1-acetylpermidine and the N1-putrescine/spermidine ratio were significantly higher, while concentration of spermidine was reduced [55]. The authors conclude that polyamine contents may serve as a metabolic marker for the diagnosis of PD.

PD progression is a typical problem, and the differences between slow and rapid forms of progression can provide valuable information for improving early diagnosis. In particular, it was found that N8-acetylspermidine was significantly elevated in fast progressive patients compared to control subjects and slowly progressive patients [56]. Balashova et al recently used mass spectrometry of plasma to diagnose early PD stages (Hoehn and Yahr stages 1, 1.5 and 2). They found an increase in the levels of polyamine metabolites such as 4-aminobutyraldehyde, $\mathrm{N}$-acetylputrescine and asymmetric dimethylarginine. It is important to emphasize that lysine breakdown activates at early stages, with an increased formation of L-lysine 1,6-lactam or fragments of lysine such as diaminohexanoate [57]. Increased lysine breakdown indicates disturbances in the cadaverine metabolism [57].

We have also investigated blood spermidine level in PD patients at both early and late stages (Hoehn and Yahr stages 1 through 4). At stage 1, spermidine level was 3.5 times higher than that in healthy individuals. At stage 2 PD, spermidine level was also significantly higher than that in controls. At stage 3 , a $63 \%$ decrease in spermidine compared to controls was registered. PD patients in this group typically manifested cognitive impairments (Min-Mental State Examination (MMSE) $=12$ ). Stage 4 showed a further decrease in spermidine content compared to controls [58].

The cited study showed that polyamine levels first increase and subsequently decrease at different stages of the disease. Therefore, it is not advisable to associate specific changes in polyamine levels with PD without knowing the stage of the condition.

\section{The role of polyamines in OS induction in PD}

A review by Hussain et al covered the general molecular mechanisms for spermine and spermidine involvement in OS induction in various pathologies, as well as possible therapies for OS correction involving these polyamines [59]. In the pre- 
sent review, we attempt to determine the role of polyamines in OS induction in the pathogenesis of PD, taking into account their selectivity in the substantia nigra.

OS activation in the substantia nigra in PD has been confirmed in biochemical studies of autopsy and biopsy samples from these brain areas. Despite the large number of studies are devoted to the molecular mechanism of OS activation in PD, this process is not currently clear [4, 5, 7, 9-11]. A sharp activation of lipid peroxidation, a decrease in glutathione and other antioxidants, as well as iron accumulation in the above-mentioned structures of the brain have been established. As most dying substantia nigra neurons are dopaminergic, a theory of PD pathogenesis based on dopamine autoxidation and quinone formation was proposed and experimentally confirmed [60].

Dopamine is an antioxidant in physiological concentrations, but with a significant increase in its content within the cell and in the presence of other inducers of the OS, dopamine exhibits prooxidant properties [60]. As mentioned above, spermine regulates the binding of dopamine to vesicles in dopaminergic neurons $[46,47]$. Under certain pathological conditions that cause a disturbance in the metabolism of spermine, one can assume the formation of an imbalance in the binding of dopamine to the vesicles, as well as the subsequent accumulation of high concentrations of dopamine and their subsequent autoxidation leading to induction of the OS. Oxidation of the polyamines plays a key role in the metabolism of polyamines, and later catabolites develop, but the mechanism is formed through which the polyamines are converted into molecules that show tremendous activity [61]. The impartment enzyme of polyamines catabolism is spermine oxydase (SMOX) [6265]. SMOX is included in the dopamine receptor signaling pathway. SMOX gene expression was intensified in PD which can lead to excessive formation of toxic aldehydes (acrolein), $\mathrm{H}_{2} \mathrm{O}_{2}$ (strong cytostatic) and ammonia (toxic substance) [66, $67]$.

Acrolein concentration was significantly increased in the substantia nigra of PD [68]. Acrolein acts as a parkinsonian neurotoxin in substantia nigra of rat brain. That was shown by acrolein local infusion in nigrostriatal dopaminergic system [69].

The reduction in the spermidine/spermine N1-acetyltransferase activity of another polyamine breakdown enzyme in PD was shown earlier [52].

It should be noted that the oxidized form of monoamine oxidase (MAO) plays a special role in the molecular mechanisms of OS startup in PD [70]. It is known that the "oxidized" form of MAO is able to change its substrate specificity and use polyamines, in particular putrescine and its metabolite-homocarnosine as a substrate [71-73].

\section{The role of polyamines in synucleinopathy, protein aggre- gation and fibrillation}

Antony et al were among the first researchers to find that the cellular polyamines putrescine, spermidine and spermine promote aggregation and fibrillation of $\alpha$-synuclein [74]. For a long time $\alpha$-synuclein was considered the main protein to be involved in the formation of Lewy bodies [75-81]. Therefore, the formation of its aggregates with spermine was suggested as one of the leading factors of PD. Through circular dichroism and fluorometric thioflavin $\mathrm{T}$ kinetic studies, it was found that the spermine-protein interaction leads to transition of $\alpha$-synuclein from non-aggregated to aggregated state. Spermine and spermidine affect the timing of this transition so that the transition period in the presence of polyamines is significantly shorter. Due to their chemical structure, polyamines can easily accelerate aggregation and fibrillation of proteins other than $\alpha$-synuclein, including amyloid-beta and tau protein [75]. In the presence of polyamines, protein fibrils form large networks, resulting in isolated condensed aggregates [75-81].

The mechanism of polyamine aggregate formation for $\alpha$-synuclein has been studied in detail. It has been established that spermine, spermidine and putrescine drastically accelerate the aggregation and fibrillation of $\alpha$-synuclein [9] by binding to the N-terminal region of the amyloid beta peptide (binding site of metal ions such as $\mathrm{Cu}^{2+}$ and $\mathrm{Zn}^{2+}$ ). Obviously, polyamines can compete with metal ions for binding to proteins. Accordingly, a hypothesis has been proposed that decreasing polyamine content in PD can contribute to correction of neurodegenerative processes in the brain [9]. The authors conclude that lower polyamine levels can be viewed as a potential therapeutic goal for the treatment of PD and that lower values can be reached by administration of compounds that either enhance the catalytic activity of the polyamine in question or inhibit polyamine synthesis. However, these conclusions do not show promise [9].

Another molecular mechanism by which polyamines affect the structure of brain proteins is their interaction with glutamyl residues of proteins, such as neuronal tubulin and transglutaminase, which form an irreversible post-translational modification of $\gamma$-glutamylamine [82]. Transglutaminase activation boosts formation of protein aggregates with polyamines [82]. On the other hand, increased polyamine content leads to cytotoxic effects by promoting formation of toxic metabolites, including aldehydes and $\mathrm{H}_{2} \mathrm{O}_{2}$. This begs the question, whether polyamine-related protein aggregation is in fact neuroprotective or neurotoxic [28].

\section{The role of glia polyamines in gliosis and OS induction in PD}

Recently numerous studies have been carried out with advanced imaging technologies (e.g. functional MRI), which demonstrated that PD is a disorder of the nervous network affecting various parts of the motor and sensory systems in the brain [14].

In neurodegenerative conditions, the functional deficiency of glioneurovascular units is determined by an imbalance in the glia/neuron ratio and the glial cell ratio between astrocytes and microglia [83-85]. In their experiments on rat brain glial cell cultures, Takano et al showed that, in the presence of fetal serum, spermidine and spermine kill microglia to a larger extent than astrocytes [83]. It was shown that polyamine-induced glial cell death was associated with OS induced by acrolein. 
Introducing antioxidants, such as reduced glutathione, cysteine and $\mathrm{N}$-acetylcysteine, into the incubation medium prevented cell death [83]. These differences in polyamine toxicity against the two types of glial cells may regulate the balance of glial activation in PD. The fact that polyamines are produced in neurons but accumulated in glia allowed Skatchkov et al [85] to propose a hypothesis that polyamines act as gliotransmitters with a neuroregulatory function. Moreover, in specific cases glial polyamines reach neurons through endothelium and brain capillaries. Investigating the role of polyamines as gliotransmitters in PD is especially important.

It is vital for brain function to maintain homeostasis between polyamine levels in glia and neurons. An imbalance in polyamine exchange can be caused by inflammation [86-88]. Niranjan showed that chronic inflammation is typical for PD [12].

Stress is an important factor affecting polyamine exchange $[29,89,90]$. Two forms of stress reactions associated with polyamine metabolism alterations have been described: 1) General or non-specific reaction; and 2) The reaction due to central neural system (CNS) stress. Thus, inflammation and stress can be seen as factors stimulating polyamine accumulation in glia, elevating their levels as well as increasing the concentration of their breakdown products. It must be noted that in PD, gliosis of the substantia nigra is present that manifests as an increase in overall glia and astrocytes [12]. It is now clear that the solution to the problem of underlying molecular mechanisms of gliosis in PD and approaches to its management lie in regulation of polyamine metabolism in the brain.

\section{Neuroprotective Effect of Spermidine}

A study using the rotenone-induced rat model of PD showed that spermidine had neuroprotective action [91]. It was established that spermidine administration concurrently with rotenone prevented loss of dopaminergic neurons, attenuated OS and neuroinflammation, and restored monoamine levels [9193].

Nematode model studies have demonstrated that spermidine has a neuroprotective action towards $\alpha$-synuclein. The studies suggest that this cytoprotective action (autophagy) accounts for the beneficial effects of spermidine administration [91-93].

\section{Conclusions}

The purpose of this review was to suggest possible answers to the question how polyamines are involved in OS induction in PD. Polyamines are ubiquitous and important components of all mammalian cells. They have numerous functions, including critical roles in nucleic acid and protein synthesis, gene expression, protein function, gene expression, protection against oxidative damage, ion channel regulation and maintenance of cellular macromolecule structures. At the early stages of PD, polyamine levels are elevated $[52,53,58]$. In PD in general, SMOX is upregulated, which leads to excessive formation of toxic aldehydes, such as acrolein, $\mathrm{H}_{2} \mathrm{O}_{2}$ and ammonia [61, 83]. This is accompanied by formation of various derivatives reflecting the dysfunction of polyamine metabolism in PD. These metabolites, especially from spermine, can cause significant toxicity damaging proteins, DNA and other cellular components $[62,64,68]$.

Especially promising is the study of spermidine metabolism in PD. For example, animal model studies have shown the neuroprotective effect of spermidine associated with autophagy activation [93].

At advanced stages, blood spermidine level decreased in PD patients who manifested declining cognitive functions [58]. It can be suggested that falling blood spermidine level is due to lower concentrations in tissues and a decrease in autophagy [93].

Polyamines' ability to alter protein structure, such as $\alpha$-synuclein, is of great importance for PD pathogenesis [74, $81,82,94]$. Glial polyamines have a regulatory effect on neurons and vice versa. The mechanism of this action has not been thoroughly studied [85].

Identifying the role of polyamines in PD pathogenesis is necessary in order to manage dysfunctions in their metabolism, which would allow more efficient treatments for cognitive disorders.

\section{Conflict of Interest}

The authors confirm that this article content has no conflict of interest.

\section{Abbreviations}

PD: Parkinson's disease; OS: oxidative stress; SMOX: spermine oxydase; ROS: reactive oxygen species; HPLC: highperformance liquid chromatography; SAMP: senescenceaccelerated mice prone; SAMR: senescence-accelerated mice resistant; PA: physical activity; NMDAR: N-methyl-D-aspartate receptor; CNS: central neural system; CSF: cerebrospinal fluid; MAO: monoamine oxidase; MMSE: Mini-Mental State Examination

\section{References}

1. Lees A. An essay on the shaking palsy. Brain. 2017;140(3):843-848.

2. Illarioshkin SN. Age-related brain diseases become the new epidemic of the XXI century. Atmosphere. Nervous Diseases. 2017;2:40-42. (in Russian).

3. Illariushkin S, Slominsky P, Shadrina M, Bagyeva B, Zagorovskaya T, Markova E, Karabanov A, et al. Heterogeneity of sporadic Parkinson's disease: a molecular approach to the problem. Annals of Clinical and Experimental Neurology. 2007;1(1):23-31. (in Russian).

4. Illarioshkin SN, Vlasenko AG, Fedotova EYu. Current means for identifying the latent stage of a neurodegenera- 
tive process. Annals of Clinical and Experimental Neurology. 2013;7(2):39-50. (In Russian).

5. Chiurchiu V, Orlacchio A, Maccarrone M. Is modulation of oxidative stress an answer? The state of the art of redox therapeutic actions in neurodegenerative diseases. Oxid Med Cell Longev. 2016;2016:7909380.

6. Abramycheva N, Fedotova E, Stepanova M, Timerbaeva S, Illarioshkin S. New approach to the molecular and genetic screening in patients with Parkinson's disease. Nevrologicheskiy Zhurnal (Neurological Journal). 2016;21(1):13-16. (in Russian).

7. Lin WC, Chou KH, Lee PL, Huang YC, Tsai NW, Chen HL, Cheng KY, et al. Brain mediators of systemic oxidative stress on perceptual impairments in Parkinson's disease. J Transl Med. 2015;13:386.

8. Fedorova T, Logvinenko A, Poleshchuk V, Illarioshkin S. The State of systemic oxidative stress during Parkinson's disease. J Neurochemical. 2017;11(4):340-345.

9. Pavlin M, Repic M, Vianello R, Mavri J. The chemistry of neurodegeneration: kinetic data and their implications. Mol Neurobiol. 2016;53(5):3400-3415.

10. Genoud S, Roberts BR, Gunn AP, Halliday GM, Lewis SJG, Ball HJ, Hare DJ, et al. Subcellular compartmentalisation of copper, iron, manganese, and zinc in the Parkinson's disease brain. Metallomics. 2017;9(10):1447-1455.

11. Yan MH, Wang X, Zhu X. Mitochondrial defects and oxidative stress in Alzheimer disease and Parkinson disease. Free Radic Biol Med. 2013;62:90-101.

12. Niranjan R. The role of inflammatory and oxidative stress mechanisms in the pathogenesis of Parkinson's disease: focus on astrocytes. Mol Neurobiol. 2014;49(1):28-38.

13. Illariosnkin SN. Modern concept of motor disorders. In the collection. "Parkinson's disease and movement disorders", Manual for physicians on the fourth national Congress on Parkinson's Disease and Movement Disorders (with international participation) (edited by Illarionkina SN, Levin OS), Moscow. 2017;13:90-91 (in Russian).

14. Illarioshkin SN. Modern ideas about the etiology of Parkinson's disease. Neurological Journal. 2015;20(4):4-13.

15. Ramani D, De Bandt JP, Cynober L. Aliphatic polyamines in physiology and diseases. Clin Nutr. 2014;33(1):14-22.

16. Nilsson J, Koskiniemi S, Persson K, Grahn B, Holm I. Polyamines regulate both transcription and translation of the gene encoding ornithine decarboxylase antizyme in mouse. Eur J Biochem. 1997;250(2):223-231.

17. Igarashi K, Kashiwagi K. Characterization of genes for polyamine modulon. Methods Mol Biol. 2011;720:51-65.

18. Williams K. Interactions of polyamines with ion channels. Biochem J. 1997;325(Pt 2):289-297.

19. Kucheryavykh LY, Benedikt J, Cubano LA, Skatchkov SN, Bukauskas FF, Kucheryavykh YV. Polyamines preserve connexin 43-mediated gap junctional communication during intracellular hypercalcemia and acidosis. Neuroreport. 2017;28(4):208-213.

20. Bachrach U, Wang YC, Tabib A. Polyamines: new cues in cellular signal transduction. News Physiol Sci. 2001;16:106-109.

21. Bell JM, Whitmore WL, Queen KL, Orband-Miller L, Slotkin TA. Biochemical determinants of growth spar- ing during neonatal nutritional deprivation or enhancement: ornithine decarboxylase, polyamines, and macromolecules in brain regions and heart. Pediatr Res. 1987;22(5):599-604.

22. Igarashi K, Kashiwagi K. Modulation of cellular function by polyamines. Int J Biochem Cell Biol. 2010;42(1):3951 .

23. Minois N, Carmona-Gutierrez D, Madeo F. Polyamines in aging and disease. Aging (Albany NY). 2011;3(8):716732.

24. Berezov TT, Makletsova MG, Siatkin SP, Rikhireva GT, Kulikova OI, Konovalova EV, Fedorova TN. [A role of polyamine metabolism in the functional activity of the normal and pathological brain]. Zh Nevrol Psikhiatr Im S S Korsakova. 2013;113(7):65-70.

25. Pegg AE. Functions of polyamines in mammals. J Biol Chem. 2016;291(29):14904-14912.

26. Pegg AE. The function of spermine. IUBMB Life. 2014;66(1):8-18.

27. Miller-Fleming L, Olin-Sandoval V, Campbell K, Ralser M. Remaining mysteries of molecular biology: the role of polyamines in the cell. J Mol Biol. 2015;427(21):33893406.

28. McCully KS. Homocysteine, infections, polyamines, oxidative metabolism, and the pathogenesis of dementia and atherosclerosis. J Alzheimers Dis. 2016;54(4):12831290.

29. Limon A, Mamdani F, Hjelm BE, Vawter MP, Sequeira A. Targets of polyamine dysregulation in major depression and suicide: Activity-dependent feedback, excitability, and neurotransmission. Neurosci Biobehav Rev. 2016;66:80-91.

30. Park MH, Igarashi K. Polyamines and their metabolites as diagnostic markers of human diseases. Biomol Ther (Seoul). 2013;21(1):1-9.

31. Cerrada-Gimenez M, Pietila M, Loimas S, Pirinen E, Hyvonen MT, Keinanen TA, Janne J, et al. Continuous oxidative stress due to activation of polyamine catabolism accelerates aging and protects against hepatotoxic insults. Transgenic Res. 2011;20(2):387-396.

32. Ha HC, Sirisoma NS, Kuppusamy P, Zweier JL, Woster PM, Casero RA, Jr. The natural polyamine spermine functions directly as a free radical scavenger. Proc Natl Acad Sci U S A. 1998;95(19):11140-11145.

33. Sava IG, Battaglia V, Rossi CA, Salvi M, Toninello A. Free radical scavenging action of the natural polyamine spermine in rat liver mitochondria. Free Radic Biol Med. 2006;41(8):1272-1281.

34. Toro-Funes N, Bosch-Fuste J, Veciana-Nogues MT, Izquierdo-Pulido M, Vidal-Carou MC. In vitro antioxidant activity of dietary polyamines. Food Res Int. 2013;51(1):141-147.

35. Park SJ, Kwak MK, Kang SO. Schiff bases of putrescine with methylglyoxal protect from cellular damage caused by accumulation of methylglyoxal and reactive oxygen species in Dictyostelium discoideum. Int J Biochem Cell Biol. 2017;86:54-66.

36. Lovaas E. Antioxidative and metal-chelating effects of polyamines. Adv Pharmacol. 1997;38:119-149. 
37. Marzabadi MR, Llvaas E. Spermine prevent iron accumulation and depress lipofuscin accumulation in cultured myocardial cells. Free Radic Biol Med. 1996;21(3):375381.

38. Kogure K, Fukuzawa K, Kawano H, Terada H. Spermine accelerates iron-induced lipid peroxidation in mitochondria by modification of membrane surface charge. Free Radic Biol Med. 1993;14(5):501-507.

39. Tadolini B. Polyamine inhibition of lipoperoxidation. The influence of polyamines on iron oxidation in the presence of compounds mimicking phospholipid polar heads. Biochem J. 1988;249(1):33-36.

40. Peng D, Wang X, Li Z, Zhang Y, Peng Y, Li Y, He X, et al. $\mathrm{NO}$ is involved in spermidine-induced drought tolerance in white clover via activation of antioxidant enzymes and genes. Protoplasma. 2016;253(5):1243-1254.

41. Belle NA, Dalmolin GD, Fonini G, Rubin MA, Rocha JB. Polyamines reduces lipid peroxidation induced by different pro-oxidant agents. Brain Res. 2004;1008(2):245251.

42. Mony L, Zhu S, Carvalho S, Paoletti P. Molecular basis of positive allosteric modulation of GluN2B NMDA receptors by polyamines. EMBO J. 2011;30(15):3134-3146.

43. Makletsova MG, Uskova NI, Bondarenko TI. [Use of gamma-aminobutyric acid from various sources in the synthesis of homocarnosine in the brain of animals of various ages]. Biokhimiia. 1992;57(9):1348-1351.

44. Sequerra EB, Gardino P, Hedin-Pereira C, de Mello FG. Putrescine as an important source of GABA in the postnatal rat subventricular zone. Neuroscience. 2007;146(2):489-493.

45. Sakamoto A, Terui Y, Yoshida T, Yamamoto T, Suzuki $\mathrm{H}$, Yamamoto $\mathrm{K}$, Ishihama $\mathrm{A}$, et al. Three members of polyamine modulon under oxidative stress conditions: two transcription factors (SoxR and EmrR) and a glutathione synthetic enzyme (GshA). PLoS One. 2015;10(4): 0124883.

46. Law CL, Wong PC, Fong WF. Effects of polyamines on the uptake of neurotransmitters by rat brain synaptosomes. J Neurochem. 1984;42(3):870-872.

47. Ritz MC, Mantione CR, London ED. Spermine interacts with cocaine binding sites on dopamine transporters. Psychopharmacology (Berl). 1994;114(1):47-52.

48. Makletsova MG, Kulikova OI, Stvolinsky SL, Fedorova TN. The content of polyamines in the brains of 10-dayold and aduit SAMP1/ SAMR1 mice, which are characterized by different rates of aging. Neurochemical Journal (Neirokhimiya). 2013;7(3):204-206.

49. Nishimura K, Shiina R, Kashiwagi K, Igarashi K. Decrease in polyamines with aging and their ingestion from food and drink. J Biochem. 2006;139(1):81-90.

50. Handa AK, Fatima T, Mattoo AK. Polyamines: bio-molecules with diverse functions in plant and human health and disease. Front Chem. 2018;6:10.

51. Liu P, Gupta N, Jing Y, Zhang H. Age-related changes in polyamines in memory-associated brain structures in rats. Neuroscience. 2008;155(3):789-796.

52. Lewandowski NM, Ju S, Verbitsky M, Ross B, Geddie ML, Rockenstein E, Adame A, et al. Polyamine pathway contributes to the pathogenesis of Parkinson disease. Proc Natl Acad Sci U S A. 2010;107(39):16970-16975.

53. Gomes-Trolin C, Nygren I, Aquilonius SM, Askmark H. Increased red blood cell polyamines in ALS and Parkinson's disease. Exp Neurol. 2002;177(2):515-520.

54. Vivo M, de Vera N, Cortes R, Mengod G, Camon L, Martinez E. Polyamines in the basal ganglia of human brain. Influence of aging and degenerative movement disorders. Neurosci Lett. 2001;304(1-2):107-111.

55. Paik MJ, Ahn YH, Lee PH, Kang H, Park CB, Choi S, Lee G. Polyamine patterns in the cerebrospinal fluid of patients with Parkinson's disease and multiple system atrophy. Clin Chim Acta. 2010;411(19-20):1532-1535.

56. Roede JR, Uppal K, Park Y, Lee K, Tran V, Walker D, Strobel FH, et al. Serum metabolomics of slow vs. rapid motor progression Parkinson's disease: a pilot study. PLoS One. 2013;8(10):e77629.

57. Balashova EE, Lokhov PG, Maslov DL, Trifonova O, Khasanova DM, Zalyalova ZA, Nijmatullina RR, et al. Plasma metabolome signature in patients with early-stage Parkinson Disease. Current Metabolomics. 2017;5:1-8.

58. Makletsova MG, Poleshchuk BB, Zilfyan AV, Avagyan SA. Level of spermine in blood pasma in patients with Parkinson's disease. NAMJ. 2017;11:33.

59. Hussain T, Tan B, Ren W, Rahu N, Dad R, Kalhoro DH, Yin Y. Polyamines: therapeutic perspectives in oxidative stress and inflammatory diseases. Amino Acids. 2017;49(9):1457-1468

60. Spencer JP, Jenner A, Butler J, Aruoma OI, Dexter DT, Jenner P, Halliwell B. Evaluation of the pro-oxidant and antioxidant actions of L-DOPA and dopamine in vitro: implications for Parkinson's disease. Free Radic Res. 1996;24(2):95-105.

61. Seiler N. Oxidation of polyamines and brain injury. Neurochem Res. 2000;25(4):471-490.

62. Pegg AE. Toxicity of polyamines and their metabolic products. Chem Res Toxicol. 2013;26(12):1782-1800.

63. Uemura T, Watanabe K, Ishibashi M, Saiki R, Kuni K, Nishimura K, Toida T, et al. Aggravation of brain infarction through an increase in acrolein production and a decrease in glutathione with aging. Biochem Biophys Res Commun. 2016;473(2):630-635.

64. Igarashi K, Uemura T, Kashiwagi K. Acrolein: An Effective Biomarker for Tissue Damage Produced from Polyamines. Methods Mol Biol. 2018;1694:459-468.

65. Pietropaoli S, Leonetti A, Cervetto C, Venturini A, Mastrantonio R, Baroli G, Persichini T, et al. Glutamate excitotoxicity linked to spermine oxidase overexpression. Mol Neurobiol. 2018;55(9):7259-7270.

66. Dumitriu A, Latourelle JC, Hadzi TC, Pankratz N, Garza D, Miller JP, Vance JM, et al. Gene expression profiles in Parkinson disease prefrontal cortex implicate FOXO1 and genes under its transcriptional regulation. PLoS Genet. 2012;8(6):e1002794.

67. Tas D, Stickley L, Miozzo F, Koch R, Loncle N, Sabado V, Gnagi B, et al. Parallel roles of transcription factors dFOXO and FER2 in the development and maintenance of dopaminergic neurons. PLoS Genet. 2018;14(3):e1007271. 
68. Shamoto-Nagai M, Maruyama W, Hashizume Y, Yoshida M, Osawa T, Riederer P, Naoi M. In parkinsonian substantia nigra, alpha-synuclein is modified by acrolein, a lipid-peroxidation product, and accumulates in the dopamine neurons with inhibition of proteasome activity. J Neural Transm (Vienna). 2007;114(12):1559-1567.

69. Wang YT, Lin HC, Zhao WZ, Huang HJ, Lo YL, Wang HT, Lin AM. Acrolein acts as a neurotoxin in the nigrostriatal dopaminergic system of rat: involvement of alphasynuclein aggregation and programmed cell death. Sci Rep. 2017;7:45741.

70. Goroshinskaia IA, Tsvetnenko EZ, Frenkel ML, Khodakova AA, Krichevskaia AA. [Monoamine oxidase activity and brain levels of histamine and polyamines in various extreme exposures]. Ukr Biokhim Zh (1978). 1987;59(2):84-86.

71. Goroshinskaya IA. Role of modification of catalytic properties of monoamine oxidase in brain in a response reaction of organism to extreme action. Vopr Med Khim. 1989;35:2-10.

72. Medvedev AE, Tipton KF. [Oxidative modification of monoamine oxidase]. Vopr Med Khim. 1997;43(6):471481.

73. Binda C, Mattevi A, Edmondson DE. Structure-function relationships in flavoenzyme-dependent amine oxidations: a comparison of polyamine oxidase and monoamine oxidase. J Biol Chem. 2002;277(27):23973-23976.

74. Antony T, Hoyer W, Cherny D, Heim G, Jovin TM, Subramaniam V. Cellular polyamines promote the aggregation of alpha-synuclein. J Biol Chem. 2003;278(5):32353240 .

75. Yatin SM, Yatin M, Varadarajan S, Ain KB, Butterfield DA. Role of spermine in amyloid beta-peptide-associated free radical-induced neurotoxicity. J Neurosci Res. 2001;63(5):395-401.

76. Illariushkin SN. Conformational diseases of the brain. Moscow: Yanus-K, 2003; p. 248 (in Prussian).

77. Gomperts SN, Locascio JJ, Marquie M, Santarlasci AL, Rentz DM, Maye J, Johnson KA, et al. Brain amyloid and cognition in Lewy body diseases. Mov Disord. 2012;27(8):965-973.

78. Petrou M, Dwamena BA, Foerster BR, MacEachern MP, Bohnen NI, Muller ML, Albin RL, et al. Amyloid deposition in Parkinson's disease and cognitive impairment: a systematic review. Mov Disord. 2015;30(7):928-935.

79. Lingor P, Carboni E, Koch JC. Alpha-synuclein and iron: two keys unlocking Parkinson's disease. J Neural Transm (Vienna). 2017;124(8):973-981.

80. Febbraro F, Giorgi M, Caldarola S, Loreni F, Romero-Ramos M. $\alpha$-Synuclein expression is modulated at the translational level by iron. NeuroReport. 2012;23(9):576-580.
81. Barrenschee M, Zorenkov D, Bottner M, Lange C, Cossais F, Scharf AB, Deuschl G, et al. Distinct pattern of enteric phospho-alpha-synuclein aggregates and gene expression profiles in patients with Parkinson's disease. Acta Neuropathol Commun. 2017;5(1):1.

82. Song Y, Kirkpatrick LL, Schilling AB, Helseth DL, Chabot N, Keillor JW, Johnson GV, et al. Transglutaminase and polyamination of tubulin: posttranslational modification for stabilizing axonal microtubules. Neuron. 2013;78(1):109-123.

83. Takano K, Ogura M, Yoneda Y, Nakamura Y. Oxidative metabolites are involved in polyamine-induced microglial cell death. Neuroscience. 2005;134(4):1123-1131.

84. Benedikt J, Inyushin M, Kucheryavykh YV, Rivera Y, Kucheryavykh LY, Nichols CG, Eaton MJ, et al. Intracellular polyamines enhance astrocytic coupling. Neuroreport. 2012;23(17):1021-1025.

85. Skatchkov SN, Woodbury-Farina MA, Eaton M. The role of glia in stress: polyamines and brain disorders. Psychiatr Clin North Am. 2014;37(4):653-678.

86. Shah P, Swiatlo E. A multifaceted role for polyamines in bacterial pathogens. Mol Microbiol. 2008;68(1):4-16.

87. Mounce BC, Olsen ME, Vignuzzi M, Connor JH. Polyamines and their role in virus infection. Microbiol Mol Biol Rev. 2017;81(4):e00029-17.

88. Gilad GM, Gilad VH. Stress-induced dynamic changes in mouse brain polyamines. Role in behavioral reactivity. Brain Res. 2002;943(1):23-29.

89. Gilad GM, Gilad VH. Overview of the brain polyaminestress-response: regulation, development, and modulation by lithium and role in cell survival. Cell Mol Neurobiol. 2003;23(4-5):637-649.

90. Bae DH, Lane DJR, Jansson PJ, Richardson DR. The old and new biochemistry of polyamines. Biochim Biophys Acta Gen Subj. 2018;1862(9):2053-2068.

91. Krauss M, Weiss T, Langnaese K, Richter K, Kowski A, Veh RW, Laube G. Cellular and subcellular rat brain spermidine synthase expression patterns suggest regionspecific roles for polyamines, including cerebellar presynaptic function. J Neurochem. 2007;103(2):679-693.

92. Buttner S, Broeskamp F, Sommer C, Markaki M, Habernig L, Alavian-Ghavanini A, Carmona-Gutierrez D, et al. Spermidine protects against alpha-synuclein neurotoxicity. Cell Cycle. 2014;13(24):3903-3908.

93. Sharma S, Kumar P, Deshmukh R. Neuroprotective potential of spermidine against rotenone induced Parkinson's disease in rats. Neurochem Int. 2018;116:104-111.

94. Titova NV, Chaudhuri KR. Non-motor symptoms of Parkinson's disease: the submerged part of the iceberg. Annals of Clinical and Experimental Neurology. 2017;11(4):5-18. (In Russ.). 